\title{
The University of South Florida free association, rhyme, and word fragment norms
}

\author{
DOUGLAS L. NELSON and CATHY L. MCEVOY \\ University of South Florida, Tampa, Florida \\ and \\ THOMAS A. SCHREIBER \\ University of Kansas, Lawrence, Kansas
}

\begin{abstract}
Preexisting word knowledge is accessed in many cognitive tasks, and this article offers a means for indexing this knowledge so that it can be manipulated or controlled. We offer free association data for 72,000 word pairs, along with over a million entries of related data, such as forward and backward strength, number of competing associates, and printed frequency. A separate file contains the 5,019 normed words, their statistics, and thousands of independently normed rhyme, stem, and fragment cues. Other files provide $n \times n$ associative networks for more than 4,000 words and a list of idiosyncratic responses for each normed word. The database will be useful for investigators interested in cuing, priming, recognition, network theory, linguistics, and implicit testing applications. They also will be useful for evaluating the predictive value of free association probabilities as compared with other measures, such as similarity ratings and co-occurrence norms. Of several procedures for measuring preexisting strength between two words, the best remains to be determined. The norms may be downloaded from www.psychonomic.org/archive/.
\end{abstract}

The purpose of this article is to make the largest free association database collected in the United States available to interested researchers and scholars. More than 6,000 participants produced nearly three quarters of a million responses to 5,019 stimulus words.

\section{What Do Free Association Norms Measure?}

With high degrees of average reliability $(r=.89)$, free association response probabilities index the likelihood that one word can cue another word to come to mind with minimal contextual constraints in effect (Nelson, McEvoy, \& Dennis, 2000). Free association probabilities provide a relative, rather than an absolute, index of what is generally called forward strength, because they are sensitive to other associates activated by the cue word that compete for production (Gillund \& Shiffrin, 1984; Nelson, Dyrdal, \& Goodmon, in press). In short, given a cue, free association probabilities index the relative accessibility of related words in memory.

We assume that free association taps into lexical knowledge acquired through world experience. Such experience creates associative structures involving the representations

This research was supported by Grant MH16360 from the National Institute of Mental Health to D.L.N. and by Grants MH45207 and AG13973 to C.L.M. In order of appearance on the project, our special thanks go to David Brooks, Joesph Wheeler, Jr., Richard Borden, MariaTeressa Bajo, Pepe Canas, Charlotte Hall, Patricia Holley, Leilani Goodmon, and Ami Willbanks for helping us. Correspondence concerning this article should be addressed to D. L. Nelson, Department of Psychology, University of South Florida, PCD Building, Room 4120, Tampa, FL 33620-8200 (e-mail: dnelson2@chuma1.cas.usf.edu). of words and the links that bind them together. These structures conform to the general constraints underlying smallworld networks (Steyvers \& Tenenbaum, in press). Like the semantic networks of WordNet, associative networks are sparse, they exhibit strong local clustering, and they have short average path lengths between words. An average of only three associative steps is required to get from any one word in our norms to any other.

Associative structures capture the shared lexical experiences of many people. They are dynamic because they are derived from the stream of everyday experience that changes gradually over time but that can produce precipitous temporary effects; for example, because of the movie, the primary free association response in our norms to instinct is basic. Norms must be used in conjunction with knowledge about current trends and local culture. They are also dynamic because they are sensitive to experience that deviates from the norm. For example, for words related to drug and alcohol use, the associative structures of substance abusers are different from the norm (Reich \& Goldman, in press; Stacy, 1997).

Although the language of association theory is used to describe the procedures and findings of experiments that rely on free association probabilities, this task appears to capture both associative knowledge and aspects of meaning. They index the knowledge that lemons are sour, that birds fly, and so on. Many researchers have attempted to draw a distinction between the effects of association and meaning by creating materials that are semantically but, ostensibly, not associatively related (e.g., for reviews, see Hutchison, 2003; Lucas, 2000). However, given the small- 
world nature of associative links, such attempts will be difficult if not futile. If only a few associative links separate most words, how can it be said that two words are not associated? The problem is not in showing that pairs of words are meaningfully related in some semantic classification, but in showing that meaningfully related pairs are not associated. Useful work on semantic classification can proceed apace without belaboring the fatuous issue of association versus meaning. Not only can we not say that two words are unassociated, but also none of the procedures for measuring preexisting strength assess the conditions of acquisition. Norms provide no knowledge of when, where, and how any measured preexisting link was learned.

\section{How Can Free Association Norms Be Used in Research?}

Free association norms are useful for several reasons. First, geneticists map genes, geologists map the earth, and psychologists are justified in mapping the links among concepts. Free association norms offer a means for constructing maps of the lexical knowledge that is most accessible to people sharing a language and a cultural heritage. Understanding the organization of word knowledge continues to be a significant problem. Second, free association probabilities can be treated as results that inform us about the nature of free association as a knowledge retrieval task (Nelson et al., 2000). Linguistic analyses of the responses can tell us about the likelihood of searching within particular domains of information as a function of information contained in the cue word.

Third, free association probabilities are useful because they predict memory performance and other behaviors (Nelson et al., 2000; Nelson, McKinney, Gee, \& Janczura, 1998). Preexisting associative structures play a significant role in both recall and recognition; for example, cued recall is more likely for stronger than for to weaker cues. Both recall and recognition are more likely when the associates of studied words are more connected to each other. Performance in standard memory tasks is influenced by the structure of preexisting knowledge about the words used in the experiments. Nearly $50 \%$ of the variance in extralist cued recall can be explained by knowledge that learners posses prior to the experiment (Nelson \& Zhang, 2000). Understanding many key issues in memory, priming, language, reasoning, development, and other areas will depend on knowing what people know and how they use this knowledge to achieve the goals of various tasks. Mental processes such as comprehension, elaboration, retrieval, and so on cannot effectively be understood in isolation from the materials on which these processes are based (Jenkins, 1979). The main justification for using normative data is that researchers benefit from knowledge of what their participants are likely to know in selecting materials for their research.

Free association norms have other uses as well. They can be compared with other norms in order evaluate the validity of different types of procedures for indexing prox- imity (e.g., Steyvers \& Tenenbaum, in press) and for evaluating statistical models of semantic representation (Dennis, 2003; Griffiths \& Steyvers, 2002). In empirical studies involving materials variables (e.g., printed frequency), associative norms can be used to avoid confounding the manipulated variable with other features. Norms also provide baseline data that can be used to determine whether some specialized population deviates from the norm (Reich \& Goldman, in press; Stacy, 1997). Free association procedures can also be used to provide an implicit assessment of the effects of training, therapy, and marketing.

\section{METHOD}

\section{Participants}

An average of $149(S D=15)$ participants were presented with 100-120 English words in a booklet containing 25-30 words per page, with the order of the pages unsystematically randomized across booklets. All received course credit for their participation.

\section{Procedure}

The participants were asked to write the first word that came to mind that was meaningfully related or strongly associated to the presented cue word. For example, given book___ they might write read. This is a discrete free association task, because each participant is asked to produce only a single associate to each word.

\section{Materials}

The great majority of the normed words are nouns (76\%), but adjectives $(13 \%)$, verbs $(7 \%)$, and other parts of speech are represented. In addition, $16 \%$, or 803 words, are identified as homographs. The selection of specific words for norming was always driven by research needs. At first, many were selected because of their potential utility as test cues for prompting the recall of related words. Others were selected because they were produced as responses in our rhyme norms, and we wanted to be able to cue the recall of the same word with either a rhyme cue or a meaning cue (e.g., Nelson $\&$ McEvoy, 1979). Some words were added because of work on priming (Bajo, 1988; Canas, 1990; McEvoy, 1988; Nelson \& Goodmon, 2002), and others were added because of interest in the concreteness issue (Nelson \& Schreiber, 1992). Many more were added in later years because they completed entire associative sets. By knowing a word's associates, as well as the associates of these associates, we could set up an $n \times n$ associative matrix in which a normed word and all of its associates were listed as column names and again as row names. This procedure allowed us to count a word's associate-to-associate links (its connectivity), as well as its associateto-target links, or resonance (e.g., Nelson, McEvoy, \& Pointer, 2003). Associative matrices were completed or nearly completed for 4,097 words (Appendix $\mathrm{C}$ in the archive).

\section{Data Analysis}

Each word and the frequencies of its responses were recorded, and D.L.N., C.L.M., or both reviewed the classifications of all responses throughout the project. Spelling errors were corrected, and rules were developed to pool items that, in our judgment, should be put together. For example, woman produced man as the dominant response, but a few participants wrote men. Instead of treating each of these responses as separate items, the count for men was pooled with the count for man. Insofar as plurals were concerned, the rule was to pool minority responses with the majority when the same word stem was involved. Similar rules were used for tense and grammatical form. In general, pooling was used reluctantly and only when it seemed justified. We engaged this practice because our interest was in assessing 
the relative strength of a given response for use in cuing and priming studies and we assumed, rightly or wrongly, that a more accurate indication would be provided by pooled than by separate tabulations. Because of this practice, scholars interested in specific forms of response, such as plurality, should be careful in using these norms.

\section{RESULTS The Database}

A brief description of what can be found in each of the four Excel format appendices is provided below. This information is presented in more detail on the Web site in the Read Me files that accompany each appendix. The references for all three appendices are available in a common file in the archive.

\section{Appendix A}

Appendix A is useful to anyone needing free association norms. All 72,186 cue-target response pairs are listed alphabetically by cue, and within cue, by target. In addition, 33 columns provide more than a million pieces of information related to associative links between the word pairs, as well as information related to individual cue and target properties. This information is represented on two Excel sheets, with A-System cues on Sheet 1 and TabZucchini cues on Sheet 2. A complete example of this table is too large for the journal, but an illustration showing the first 8 columns for the cue word $\mathrm{A}$ is shown in Table 1. Finally, this file can be realphabetized by target, and this ordering will display all of the normed cues that produce that target as an associate, along with the linked information. This format will be useful for anyone who has already selected a target word and is looking for a potential cue or prime word.

\section{Appendix B}

Appendix B presents the 5,019 normed words, listed alphabetically, and associative as well as frequency and other data that will be useful as targets for experiments on single-item recognition and for experiments on nonsemantic cuing. This appendix presents independent set size and strength norms for beginning stem cues, ending stem cues, beginning fragment cues, and ending fragment cues. Each of the targets presented in this file can be looked up in Appendix A whenever an investigator needs both a nonsemantic and a semantic cue for the same target wordfor example, good and be _ as cues for best. All of the target words appearing in this file are cross-referenced in the meaning files, making it possible to manipulate type of cue or type of prime while holding normative cueto-target strength, as well as other word characteristics, constant. Table 2 provides a list of what can be found in Appendix B.

\section{Appendix C}

Appendix C contains an alphabetical listing of the $n \times n$ associative matrices showing associate-to-target links (resonance) and associate-to-associate links (connectivity) for thousands of normed words. The matrices provide a concrete representation of associative structure for a given word. As is shown in Table 3, the word dinner has a set of five associates, including supper, eat, lunch, food, and meal. These norms were created by norming dinner and then, with independent samples of participants, norming each of its associates. Dinner is shown in the top left corner of the matrix, and its associates are printed in full in the first column. The first three letters of each associate is also printed at the top of the remaining columns.

The first row provides the target and the free association probabilities for each of its associates (the self-strength of dinner is assigned a 1.0 for theoretical reasons). The remaining rows should also be read from left to right. In the first column, they show the free association probabilities for each associate-to-target link (e.g., supper produces dinner with a probability of .55). In the remaining columns, they show the probabilities of associate-to-associate links (e.g., supper produces eat with a probability of .02). The

Table 1

An Illustration of Part of the Information in Appendix A for the First Word in the Norms

\begin{tabular}{llcccccc}
\hline & & \multicolumn{2}{c}{ No. Subjects } & & \\
Cues & Target & Sample & $\begin{array}{c}\text { Producing } \\
\text { Target }\end{array}$ & $\begin{array}{c}\text { Forward } \\
\text { Strength }\end{array}$ & $\begin{array}{c}\text { Backward } \\
\text { Strength }\end{array}$ & $\begin{array}{c}\text { Mediated } \\
\text { Strength }\end{array}$ \\
\hline A & ALPHABET & YES & 152 & 10 & 0.066 & 0.046 & 0.002 \\
A & AN & NO & 152 & 4 & 0.026 & missing & 0 \\
A & AND & NO & 152 & 2 & 0.013 & missing & 0 \\
A & APPLE & YES & 152 & 2 & 0.013 & 0 & 0 \\
A & B & NO & 152 & 69 & 0.454 & missing & 0 \\
A & GRADE & YES & 152 & 9 & 0.059 & 0.277 & 0 \\
A & GREAT & YES & 152 & 2 & 0.013 & 0 & 0 \\
A & LETTER & YES & 152 & 6 & 0.039 & 0 & 0.003 \\
A & ONE & YES & 152 & 2 & 0.013 & 0 & 0 \\
A & PLUS & YES & 152 & 5 & 0.033 & 0 & 0 \\
A & THE & NO & 152 & 10 & 0.066 & missing & 0 \\
A & WORD & YES & 152 & 2 & 0.013 & 0 & 0 \\
A & Z & NO & 152 & 3 & 0.020 & missing & 0 \\
\hline
\end{tabular}


Table 2

Information in Appendix B

\begin{tabular}{|c|c|}
\hline Column Label & Definition \\
\hline Targets & Words normed in free association \\
\hline Sample Size & Number of participants \\
\hline Set Size & Number of different target associates, or network size \\
\hline Set Size + Idiosyncratic & Target set size + idiosyncratic responses \\
\hline Frequency $(\mathrm{K} \& \mathrm{~F})$ & Printed frequency in Kučera and Francis (1967) norms \\
\hline Concreteness (Scale 1-7) & Concreteness ratings for the target word \\
\hline Homograph? (Letter = Yes) & Is the target a homograph? Letter indicates norms used. \\
\hline Part of Speech & Part of speech of the target determined by dictionary \\
\hline Mean Connectivity & Mean number of associate-to-associate links for target \\
\hline Connectivity Strength & Summed strength of target's associate-to-associate links \\
\hline Resonance Probability & Probability that target's associates produce it as an associate \\
\hline Resonance Strength & Summed strength of target's associate-to-target links \\
\hline Accessibility Index & Number of cues that produce the target as a response \\
\hline Non-Responses & No response, illegible responses, swear words \\
\hline Ending Stem Set Size & $\begin{array}{l}\text { Number of different words produced in free association } \\
\text { after hearing end of target as a rhyme cue }\end{array}$ \\
\hline Ending Stem Strength & $\begin{array}{l}\text { Probability of producing target in free association } \\
\text { after hearing end of target as a rhyme cue }\end{array}$ \\
\hline Beginning Stem Set Size & $\begin{array}{l}\text { Number of different words produced in free association } \\
\text { after hearing beginning letters of target as a cue }\end{array}$ \\
\hline Beginning Stem Strength & $\begin{array}{l}\text { Probability of producing target in free association } \\
\text { after hearing beginning letters of target as a cue }\end{array}$ \\
\hline Ending Fragment Cues & $\begin{array}{l}\text { Words with missing letters replaced by spaces presented } \\
\text { as free association cues }\end{array}$ \\
\hline Ending Fragment Set Size & $\begin{array}{l}\text { Number of different words produced in free association for a } \\
\text { visually presented ending fragment cue }\end{array}$ \\
\hline Ending Fragment Strength & $\begin{array}{l}\text { Probability of producing target in free association for } \\
\text { visually presented ending fragment cue }\end{array}$ \\
\hline Beginning Fragment Cues & $\begin{array}{l}\text { Words with missing letters replaced by spaces presented } \\
\text { as free association cues }\end{array}$ \\
\hline Beginning Fragment Set Size & $\begin{array}{l}\text { Number of different words produced in free association for a } \\
\text { visually presented beginning fragment cue }\end{array}$ \\
\hline Beginning Fragment Strength & $\begin{array}{l}\text { Probability of producing target in free association for } \\
\text { visually presented beginning fragment cue }\end{array}$ \\
\hline
\end{tabular}

associates of dinner are highly connected, but the associates for most words are sparsely connected. In PIER2 (Nelson \& Zhang, 2000), the sum of the strengths in the first column provides an estimate of resonance strength (for dinner, the resonance strength is 2.03). The sum of the strengths in the remaining columns provides an estimate of connectivity strength (for dinner, the connectivity strength is $.62+.68+.20+1.36+.20=3.06)$. The sum of resonance and connectivity strength estimates the activation strength of the target when studied $(2.03+3.07=$ 5.09). Finally, the absence of a value in the matrix is interpreted as an indication either that there is no connection or that it is too weak to be measured by direct, singleresponse free association.

Table 3

$\boldsymbol{n} \times \boldsymbol{n}$ Associative Matrix for Dinner

\begin{tabular}{lcccccc}
\hline \multicolumn{1}{c}{ Cue } & DIN & SUP & EAT & LUN & FOO & MEA \\
\hline DINNER & 1.00 & 0.54 & 0.11 & 0.10 & 0.09 & 0.09 \\
SUPPER & 0.55 & - & 0.02 & 0.03 & 0.17 & 0.01 \\
EAT & & & - & & 0.40 & 0.02 \\
LUNCH & 0.27 & 0.02 & 0.08 & - & 0.21 & 0.06 \\
FOOD & & & 0.41 & 0.01 & - & 0.02 \\
MEAL & 0.21 & 0.06 & 0.06 & 0.06 & 0.49 & - \\
Summed strength & 2.03 & .62 & .68 & .20 & 1.36 & .20 \\
\hline
\end{tabular}

\section{Appendix D}

Appendix D presents all of the normed words and their idiosyncratic responses. Idiosyncratic responses are not presented in Appendix A, because they are produced by a single individual and are unreliable (Nelson \& Schreiber, 1992). The participants produced 111,157 idiosyncratic responses, which comes to an average of 22.15 such responses for each normed word. On average, more idiosyncratic responses are produced than responses given by 2 or more participants. This production was highly variable across different words, ranging from 1 to 73 responses, with a standard deviation of 10 words. Only 111,026 idiosyncratic responses are reported in this appendix, because some were missing due to of errors of various types. Rather than spending weeks tracking down the errors, we are simply reporting what we have. As an illustration of what can be found in this appendix, Table 4 provides the idiosyncratic responses for the word dinner. As can be seen, these associates tend to be related to the cue, but because they are unreliable, we never included them in the estimate of set size for research purposes. A column presenting the sum of set size plus idiosyncratic responses is available in Appendix B for those who may be interested in comparing values. 
Table 4

The Normed Words, Their Idiosyncratic Responses, and the Probabilities of These Responses

\begin{tabular}{clc}
\hline Normed Word & Response & Probability \\
\hline DINNER & BELL & .009 \\
DINNER & DANCE & .009 \\
DINNER & GUEST & .009 \\
DINNER & HUNGRY & .009 \\
DINNER & JACKET & .009 \\
DINNER & PARTY & .009 \\
DINNER & REPAST & .009 \\
DINNER & STEAK & .009 \\
DINNER & TABLE & .009 \\
\hline
\end{tabular}

\section{DISCUSSION}

Why should free association norms, as opposed to other procedures, be used to estimate the preexisting strength between two words? One reason is that free association has a long history as a reliable task for measuring connection strengths (Cramer, 1968; Deese, 1965; Jenkins \& Palermo, 1964; Nelson et al., 2000). Another reason is that free association offers two advantages over rating pairs of words for associative similarity. Norming a single word provides a list of its associates, whereas a similarity rating provides a measure for a single pair. Mapping a word's associative structure in an $n \times n$ format is less complicated with free association, because a word's associates do not have to be discovered by collecting ratings for thousands of words. The second advantage is that free association probabilities predict recall success more accurately than do ratings in both extralist and intralist cuing procedures (Nelson et al., in press). When it comes to predicting recall, free association probabilities perform better than ratings. However, recent work on co-occurrence statistics offers a promising alternative for predicting memory performance (Landauer \& Dumais, 1997). The assumption is that the co-occurrence of words in text can be used to index semantic similarity. A text that mentions lions is likely to mention animals that lions prey upon. Latent semantic analysis (LSA) uses co-occurrences and a technique known as single-value decomposition for locating words in semantic space. Tens of thousands of words and texts are involved in the computations, and words appearing in similar texts are placed in similar regions of a multidimensional space of 200-400 dimensions.

LSA's similarity index may be related to free association probabilities and may predict recall success. It is modestly correlated with forward strength in our norms ( $r=.27, n=49,362$; Maki, McKinley, \& Thompson, 2004). Unfortunately, LSA similarity is more weakly correlated with extralist cued recall probability $(r=.07, n=$ $2,201)$ than with free association probabilities $(r=.30$, $n=2,201$; see also Steyvers, Shiffrin, \& Nelson, in press). However, although LSA statistics do not predict recall, they effectively predict reading (Landauer \& Dumais, 1997; Landauer, Foltz, \& Laham, 1998). Free association is a better predictor for recall because both free association and cued recall require the recovery of a related word from memory, given a cue. In contrast, LSA similarity is more likely to be a better predictor of reading comprehension than is free association, because textual material provides the basis for measuring semantic similarity. Different kinds of maps for measuring lexical knowledge are likely to be needed for predicting different kinds of cognitive performance.

Free association is more useful for predicting recall than are similarity ratings or LSA, but it has shortcomings. First, the discrete free association procedure avoids problems of response chaining and retrieval inhibition (McEvoy \& Nelson, 1982), but the single-response requirement reduces the chances of observing weak associates (Nelson et al., 2000). Free association probabilities underestimate the strengths of directly linked but weak associates, and this point should be kept in mind when using norms to build materials for research.

The second limitation is that free association provides a relative, not an absolute, index of strength. Knowing that the response read is produced by $43 \%$ of the participants to the cue book does not tell us how strong this response is in any absolute sense; it indicates that this response is stronger than study, which was produced by $5.5 \%$ of the participants. Free association norms, like similarity ratings, provide reasonable approximations to interval scale measures, but as far as we know, no measure of absolute preexisting strength exists. Furthermore, free association provides an index of strength that comes without an independent measure of variance. It is a proportion, so it has a binomial variance that is predictable from this proportion, but this shortcoming may limit the usefulness of this index in some situations.

Researchers also need to be concerned about the generalizability of free association norms across cultures and regions. Kiss, Armstrong, and Milroy (1972) normed more than 8,000 words in Great Britain. When we compared the associates of words common to the two sets of norms, we decided that the differences were too great for the kind of work we anticipated doing, so we continued collecting our own. Free association is also sensitive to regional differences. For example, associates to apple may be different in Florida than in other locations where apple trees and traditions of apple pie and picking apples are more frequent. Although Floridians know about apples, many have never seen or climbed a real apple tree, and their most frequent response is red, with tree and pie given infrequently. Although the present norms have been used successfully in many places, the important point is that free association norms, or norms of any kind, must be used with sensitivity to local word usage, as well as to events that may temporarily alter strength. Finally, free association norms are sensitive to personal individual differences in experience. Responses to drug- and alcohol-related words are stronger for drug users (Stacy, 1997) and heavy drinkers (Reich \& Goldman, in press). Cultural, regional, temporal, and individual influences must be kept in mind when using free association norms in constructing materials for experiments.

These considerations indicate that free association is an imperfect but useful tool. Difficult as they are to collect, 
such norms offer better maps for predicting performance in certain cognitive tasks, and if anything, more norms are needed. A case can be made for a national norming study involving thousands of words. The measurement issue begs for additional research, because the importance of mapping lexical knowledge justifies such attention if the field is going to answer the fundamental question of how word knowledge interacts with ongoing cognitive performance.

\section{REFERENCES}

BAJO, M. T. (1988). Semantic facilitation with pictures and words. Journal of Experimental Psychology: Learning, Memory, \& Cognition, 14 579-589.

CANas, J. J. (1990). Associative strength effects in the lexical decision task. Quarterly Journal of Experimental Psychology, 42, 121-145.

Cramer, P. (1968). Word association. New York: Academic Press.

DEESE, J. (1965). The structure of associations in language and thought. Baltimore: Johns Hopkins University Press.

DENNIS, S. (2003). A comparison of statistical models for the extraction of lexical information from text corpora. In Proceedings of the TwentyFifth Conference of the Cognitive Science Society. http://www.cognitive sciencesociety.org/.

Gillund, G., \& Shiffrin, R. M. (1984). A retrieval model for both recognition and recall. Psychological Review, 91, 1-67.

Griffiths, T. L., \& STEYVERS, M. (2002). A probabilistic approach to semantic representation. In Proceedings of the Twenty-Fourth Annual Conference of Cognitive Science Society. http://www.cognitivescience society.org/.

Hutchison, K. A. (2003). Is semantic priming due to association strength or featural overlap? A microanalytic review. Psychonomic Bulletin \& Review, 10, 785-813.

JENKINS, J. J. (1979). Four points to remember: A tetrahedral model of memory experiments. In L. S. Cermak \& F. I. M. Craik (Eds.), Levels of processing in human memory (pp. 429-446). Hillsdale, NJ: Erlbaum.

Jenkins, J. J., \& PALERMo, D. S. (1964). Word association norms. Minneapolis: University of Minnesota Press.

Kiss, G. R., Armstrong, C. A., \& Milroy, R. (1972). An associative thesaurus of English (microfilm version). Wakefield, MA: E. P. Microforms.

KUČERA, H., \& FRANCIS, W. N. (1967). Computational analysis of presentday American English. Providence, RI: Brown University Press.

Landauer, T. K., \& Dumais, S. T. (1997). A solution to Plato's problem: The latent semantic analysis theory of acquisition, induction and representation of knowledge. Psychological Review, 105, 221-240.

Landauer, T. K., Foltz, P. W., \& Laham, D. (1998). Introduction to latent semantic analyses. Discourse Processes, 25, 259-284.

LuCAs, M. (2000). Semantic priming without association: A metaanalytic review. Psychonomic Bulletin \& Review, 7, 618-630.

MaKi, W. S., McKinley, L. N., \& Thompson, A. G. (2004). Semantic distance norms computed from an electronic dictionary (WordNet). Behavior Research Methods, Instruments, \& Computers, 36, 421-431.

McEvoy, C. L. (1988). Automatic and strategic processes in picture naming. Journal of Experimental Psychology: Learning, Memory, \& Cognition, 14, 618-626.

McEvoy, C. L., \& Nelson, D. L. (1982). Category name and instance norms for 106 categories of various sizes. American Journal of Psychology, 95, 581-634.

Nelson, D. L., Dyrdal, G. M., \& Goodmon, L. B. (in press). What is preexisting strength? Predicting free association probabilities, similarity ratings, and cued recall probabilities. Psychonomic Bulletin \& Review.

Nelson, D. L., \& Goodmon, L. B. (2002). Experiencing a word can prime its accessibility and its associative connections to related words. Memory \& Cognition, 30, 380-398.

Nelson, D. L., \& McEvoy, C. L. (1979). Encoding context and set size. Journal of Experimental Psychology: Human Learning \& Memory, 5 , 292-314.

Nelson, D. L., McEvoy, C. L., \& Dennis, S. (2000). What is free association and what does it measure? Memory \& Cognition, 28, 887-899.
Nelson, D. L., McEvoy, C. L., \& Pointer, L. (2003). Spreading activation or spooky action at a distance? Journal of Experimental Psychology: Learning. Memory, \& Cognition, 29, 42-52.

Nelson, D. L., McEvoy, C. L., \& Schreiber, T. A. (1999). The University of South Florida Word Association, Rhyme and Fragment Norms [On line]. http://luna.cas.usf.edu/ nelson/.

Nelson, D, L., McKinney, V. M., Gee, N. R., \& Janczura, G. A. (1998). Interpreting the influence of implicitly activated memories on recall and recognition. Psychological Review, 105, 299-324.

Nelson, D. L., \& SChreIBER, T. A. (1992). Word concreteness and word structure as independent determinants of recall. Journal of Memory \& Language, 31, 237-260.

Nelson, D. L., \& Zhang, N. (2000). The ties that bind what is known to the recall of what is new. Psychonomic Bulletin \& Review, 7, 604 617.

ReIch, R. R., \& Goldman, M. S. (in press). Exploring the alcohol expectancy memory network: The utility of free associates. Psychology of Addictive Behaviors.

StaCY, A. W. (1997). Memory activation and expectancy as prospective predictors of alcohol and marijuana use. Journal of Abnormal Psychology, 106, 61-73.

Steyvers, M., Shiffrin, R. M., \& Nelson, D. L. (in press). Word association spaces for predicting semantic similarity effects in episodic memory. In A. Healy (Ed.), Cognitive psychology and its applications: Festschrift in honor of Lyle Bourne, Walter Kintsch, and Thomas Landauer. Washington, DC: American Psychological Association.

Steyvers, M. \& TenEnbaum, J. (in press). Graph theoretic analyses of semantic networks: Small worlds in semantic networks. Cognitive Science.

\section{ARCHIVED MATERIALS}

The norms and links may be accessed through the Psychonomic Society's Norms, Stimuli, and Data archive, http://www.psychonomic org/archive/.

To access these files or links, search the archive for this article using the journal (Behavior Research Methods, Instruments, \& Computers), the first author's name (Nelson), and the publication year (2004).

FILE: Nelson-BRMIC-2004.zip.

DESCRIPTION: The compressed archive file contains four appendices, and each appendix contains a Read Me file that explains its contents These materials are available in .xls, .csv, .pdf, and .txt formats. The appendices contain the norms developed by Nelson, McEvoy, and Schreiber (1999), with each appendix represented in Microsoft Excel 2001 Workbook for the Macintosh. Tables at the beginning of Appendices A and B provide quick reference to the definitions of the column names. Appendix A presents $28.5 \mathrm{MB}$ (5 MB compressed) of free association data, along with other strength measures and item characteristic measures, for more than 72,000 word pairs on two Excel pages (assigning additional memory to Excel may be necessary). Appendix B presents the 5,000 words normed in free association, many columns of data on their characteristics, as well as rhyme, beginning stem, and word fragment cues that produce these words as associates (1.2-MB/240K compressed). Appendix $C$ presents the $n \times n$ associative matrices for over 4,000 words (20.4-MB/3.6MB compressed), and Appendix D presents the idiosyncratic responses for the words normed in Appendices A and B.

LINK: http://luna.cas.usf.edu/ nelson/.

DESCRIPTION: The site provides extralist cued recall and single-item recognition databases for thousands of items taken from dozens of experiments done in our lab. These files can be downloaded and used to determine what item characteristics predict performance and to evaluate models of cued recall and memory.

AUTHOR's E-MAIL ADDRESs: dnelson2@chuma1.cas.usf.edu. AUTHOR's WeB SITE ADDREss: http://luna.cas.usf.edu/ nelson/.

(Manuscript received December 2, 2003; revision accepted for publication July 13, 2004.) 